\title{
The role of the acquired immune response in systemic sclerosis
}

\author{
Carlo Chizzolini $^{1} \cdot$ Francesco Boin $^{2}$
}

Received: 14 May 2015 / Accepted: 16 June 2015 /Published online: 8 July 2015

(C) Springer-Verlag Berlin Heidelberg 2015

\begin{abstract}
Profound alterations characterize the adaptive immune response in systemic sclerosis, and several layers of evidence support a prominent role exerted by immune cellular effectors and humoral mediators in the pathogenesis of this disease. These include (i) the presence of oligoclonal T cells in tissues undergoing fibrosis consistent with (auto)antigen-specific recruitment, (ii) the preferential expansion of polarized $\mathrm{CD} 4+$ and $\mathrm{CD} 8+\mathrm{T}$ cells producing pro-fibrotic cytokines such as IL-4 and IL-13, (iii) the presence of increased number of cells producing mediators belonging to the IL-17 family, including IL-22, which may drive and participate in inflammatory pathways involving epithelial cells as well as fibroblasts, (iv) the deficient or redirected function of T regulatory cells favoring fibrosis, and (v) the enhanced expression of CD19 and CD21 on naïve B cells, and the upregulation of co-stimulatory molecules in mature B cells, which together with the increased levels of B cell activating factor (BAFF) underlie the propensity to an exaggerated humoral response possibly favoring fibrogenesis. Despite all the progress made in understanding the features of the aberrant immune response in scleroderma, it remains unclear whether the activation of immune effector pathways ultimately drives the disease pathogenesis or rather represents a defective attempt to limit or
\end{abstract}

This article is a contribution to the Special Issue on Immunopathology of Systemic Sclerosis - Guest Editors: Jacob M. van Laar and John Varga

Carlo Chizzolini

Carlo.Chizzolini@unige.ch

1 Immunology and Allergy, University Hospital and School of Medicine, Rue Gabrielle Perret-Gentil 4, 1211 Geneva 14, Switzerland

2 Scleroderma Center, University of California, San Francisco, CA, USA even reverse excessive extracellular matrix deposition and progressive vasculopathy, the main hallmarks of this disease.

Keywords Systemic sclerosis $\cdot$ Scleroderma $\cdot$ T cells $\cdot$ Th1 cells $\cdot$ Th 2 cells $\cdot$ Th17 cells $\cdot$ Treg cells $\cdot$ B cells $\cdot$ Fibroblast . Integrin · Cytokine · Interleukin · BAFF · IL-22 · Extracellular matrix $\cdot$ Collagen

\section{Introduction}

Systemic sclerosis (SSc) is characterized by three peculiar features including excessive deposition of extracellular matrix leading to fibrosis and organ dysfunction, vasculopathy with micro- and macro-vasculature damage causing hypoperfusion and hypo-oxygenation of the tissues, and finally autoimmunity, which reflects the coordinated activation of innate and adaptive immune responses. How these three features interconnected is a matter of intense ongoing research, and we do not have any definitive evidence establishing the hierarchical relationship between them. In particular, it is debated whether the activation of the immune system, including its inflammatory component, causes or is a consequence of the vasculopathy and fibrosis. The following points can be considered in favor of a prominent role of an aberrant immune response in the pathogenesis of SSc. (i) Histological studies indicate that an inflammatory infiltrate is present in very early stages of SSc, even before clinically overt vasculopathy and anatomical endothelial cell damage become established [84]. (ii) T cells infiltrating the skin in SSc or present in the peripheral blood express an oligoclonal $\mathrm{T}$ cell receptor (TcR) repertoire suggestive of an antigen (possibly autoantigen)-driven response [55, 93]. (iii) Fibroblasts adjacent to dermal inflammatory infiltrate rich in T cells and monocytes show enhanced synthesis of collagen when studied by in situ hybridization 
[29, 47, 100]. (iv) Genome-wide association studies, which are intrinsically unbiased, have identified several polymorphisms conferring susceptibility to SSc located, in the large majority, within gene relevant fore innate and adaptive immune responses [2, 14, 39, 40, 71, 85]. In this respect, it is important to emphasize how it has been known for a long time that certain HLA haplotypes are associated with SSc and that, more intriguingly, their alleles differ according to limited versus diffuse SSc subset, autoantibody status, ethnic background, and geographical location suggesting that the immune response may be set in motion by different antigens in individuals with different ancestries [7]. (v) While therapies based on conventional immunosuppressive agents have provided limited benefit to control fibrotic outcomes, intense immunosuppression followed by reconstitution of the immune system by autologous hematopoietic stem cells (HSCT) appears to be a strategy capable of reducing more rapidly and effectively skin fibrosis as well as stabilizing if not improving interstitial lung disease [18, 19, 111]. In addition, also, the underlying vasculopathy may benefit from aggressive immunosuppression [30]. (vi) Finally, SSc clinical features and autoantibody profile may overlap in a given individual with those of other connective tissue disorders (i.e., systemic lupus erythematosus) in which the autoimmune nature of the disease process has been widely accepted.

The adaptive or acquired arm of the immune system is mainly represented by $\mathrm{T}$ and $\mathrm{B}$ cells, which are provided with clonally variable antigen-binding receptors selected during cell maturation. After the encounter with the cognate antigens, these cells retain immunological memory and, in the case of $B$ cells, can expand the repertoire of antigen (epitope) recognition, increase the affinity their receptors, and drive immunoglobulin isotype switching. As a rule, which particularly applies to autoimmune diseases, the adaptive immune response initiates only when cells of the innate immune system become activated and express molecules indicating danger. Thus, it is important to consider that also within SSc and other fibrotic disorders of autoimmune origin, the activation of the innate immune system chronologically precedes that of the adaptive system. The dialog between these two systems is mediated by cell-cell interactions as well as by soluble mediators, which clearly play an essential role to initiate and amplify the disease process. In this review, we will mainly focus on the role of $\mathrm{T}$ and $\mathrm{B}$ cell responses in $\mathrm{SSc}$, delineating only some aspects of the innate immune response, which modulate $\mathrm{T}$ and $\mathrm{B}$ cell function.

T cells in SSc and fibrosis $T$ cells are extremely heterogeneous in terms of $\mathrm{T}$ cell receptor (TcR) expression, effector function, and usage of their accessory molecules. While in previous decades, the research enquiry was devoted to study the main CD4+ helper and CD8+ cytolytic T cellular subsets as well as to the characterized T cell variants bearing the $\alpha / \beta$ or $\gamma / \delta \mathrm{TcR}$; most of the recent attention has been focused on the identification of unique cytokine secretion patterns in $\mathrm{T}$ cells obtained from the peripheral blood or detected within the affected tissues in SSc [107]. In fact, selective cytokine production by $\mathrm{T}$ lymphocytes has been considered to have a major impact on endothelial cell and fibroblast function, with possible effects promoting or inhibiting vascular disease and excessive collagen synthesis.

Th1 and Th2 cells Classically, CD4+ T helper cells have been categorized into the Th1 and Th2 subsets. Of major importance for the fate determination of CD4+ T helper cells is the cytokine milieu where $\mathrm{T}$ cell activation takes place. Thus, in the presence of IL-12 and interferons, T helper precursor cells become Th1 and high producers of IFN- $\gamma$, while in the presence of IL- 4 and IL-2, they become Th2 and high producers of IL-4, IL-5, and IL-13 $[5,126]$. Transcriptome analysis in animal models has shown that genes involved in wound healing and fibrosis are associated with Th2-polarized responses, characterized by the production of IL-4, IL-5, and IL-13 as opposed to Th1-polarized responses characterized by IFN $-\gamma$ production $[42,94]$. Considerable evidence indicates that indeed type 2 polarized responses are important for fibrosis development [116-118]. Initial observations suggested that T cells infiltrating the skin and other organs in SSc were functionally heterogeneous but preferentially polarized towards IFN- $\gamma$ production and therefore belonging to the Th1-like subset [28]. With the development of more refined techniques and increased knowledge about $\mathrm{T}$ cell function, it has become more evident and widely documented that $\mathrm{T}$ cells secreting high levels of IL-4 (Th2-like subset) distinctly populate SSc tissues $[9,12,25,70,82,99]$. These comprise classical CD4+ $\mathrm{T}$ helper cells $[70,99]$ but also $\mathrm{CD} 8+\mathrm{T}$ cells $[9]$ as well as $\mathrm{T}$ cells expressing simultaneously CD4 and CD8 and carrying both helper and cytolytic function, together with high production of IL-4 [82]. More recently, CD8+ T cells characterized by high production of IL-13 and expression of GATA-3 have been detected within the repertoire of "type 2 " cells present in SSc peripheral blood and involved skin, particularly during early phases of the disease $[35,36,72]$. While evidence indicating that the production of IL-4 and IL-13 is increased in SSc skin or lung, no polymorphisms associated with SSc or its phenotypes have been found in the genes of these cytokines [16]. In general, it is accepted that IL-4 and IL-13 enhance collagen synthesis $[80,83]$, while IFN- $\gamma$ yields inhibitory effects [90] (Fig. 1). In contrast with this notion, evidence has suggested that when fibroblasts are activated by $T$ cell contact, inhibition rather than enhancement of type I collagen production is observed with both Th1 and Th2 cells [21, 24, 40, 41]. The molecular mechanisms are different, since IFN- $\gamma$ neutralization reverses type 1 (Th1)-mediated inhibition, while Th2 cell-dependent inhibition is essentially mediated by tumor necrosis factor (TNF). Furthermore, the inhibition of collagen synthesis mediated by $\mathrm{T}$ cell contact is dominant over the pro- 


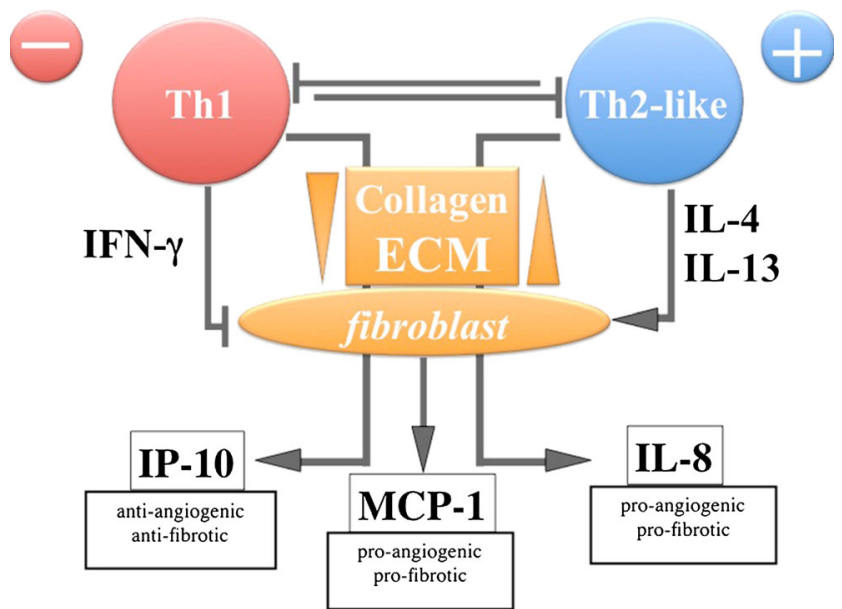

Fig. 1 Opposing roles of Th1 and Th2-like cells in respect of ECM deposition and fibroblast inflammatory responses. Arrows and arrowheads indicate stimulation; blunted-ends indicate inhibition

fibrotic responses induced by IL-4 and TGF- $\beta$. Importantly, it should be stressed that SSc fibroblasts are resistant to T cell contact-dependent inhibition, which likely reflects intrinsic differences with normal fibroblasts [21, 24]. A possible paradoxical function has been described also for TNF in the context of SSc. In fact, TNF normally exerts a profound (in vitro) anti-fibrotic effect by downregulating type I collagen production and by enhancing the production of matrix metalloproteinases (MMP), including MMP-1, which degrades native collagens $[23,105]$. In contrast, it has been shown that costimulation of T cells obtained from the skin of SSc patients with TNF can enhance their ability to stimulate collagen production by fibroblasts [45]. Finally, Th1 and Th2 cells differentially regulate the production of chemokines by fibroblasts, Th1 preferentially inducing the anti-fibrotic anti-angiogenic IP-10 and Th2 inducing the pro-fibrotic, pro-angiogenic IL-8 [22] (Fig. 1).

Regulatory $\mathbf{T}$ cells Regulatory $\mathrm{T}$ cells (Tregs) are thought to play a pivotal role in maintaining immunologic self-tolerance and preventing autoimmunity. Their ability to limit potentially dangerous immune responses and to regulate the function of other $\mathrm{T}$ cells is exerted by a variety of mechanisms including the production of immunosuppressive cytokines (TGF- $\beta$, IL10 ), the inhibition by contact of effector T cells or antigenpresenting cells via surface molecules such as CTLA-4, or the expression of enzymes such as indoleamine 2,3-deoxygenase, which by reducing the availability of the essential amino acid tryptophan drives potent anti-proliferative effects [91]. At least two main types of Tregs are recognized: the natural Treg (nTreg) and the inducible Treg (iTreg) subsets. nTregs are $\mathrm{CD} 4+\mathrm{T}$ cells generated in the thymus during the process of negative selection which allow retention of cells bearing $\mathrm{TcR}$ with an intermediate affinity for self-antigens associated with a developmental program leading to a regulatory phenotype
[78]. iTregs develop from naïve, mature CD4+ T cells after encountering their nominal antigen within secondary lymphoid organs in the presence of TGF- $\beta$ and high levels of IL-2 [126]. An intrinsic problem when studying Tregs, particularly in humans, is that no definitive marker faithfully segregates exclusively with their regulatory function as their phenotype is characterized by a substantial degree of plasticity [92]. Markers used for their identification include the intracellular expression of the transcription factor FOXP3, the surface high expression of $\mathrm{CD} 25$, the combination of CD45 isoforms with the above molecules [75], and the expression of CD127. This may explain why the literature concerning Tregs in SSc does not provide homogenous data and a uniformed view regarding their role and function. Some authors have reported that the number of Tregs is markedly increased in all clinical SSc phenotypes, but these Tregs exhibit a diminished capacity to control CD4 effector T cells $[6,87,103]$. Furthermore, this defective function seems to correlate with lower expression of CD69 and TGF- $\beta$. Others have found a quantitative reduction of Tregs in the skin and peripheral blood of affected patients $[6,66]$. In particular, Mathian et al. have reported that "activated" Tregs (CD4 CD45RA ${ }^{-}$FOXP $\left.3{ }^{\text {bright }} \mathrm{CD} 25^{\text {bright }}\right)$ are decreased in SSc patients at any disease stage, while "resting" Treg (CD4 CD45RA $\left.{ }^{+} \mathrm{FOXP} 3^{+} \mathrm{CD} 25^{+}\right)$frequency decline in late phases of SSc [66]. Their data show that both subsets retain an intact suppressive function and support the possibility that the quantitative deficit of Tregs may drive activation and proliferation of effector T cells. In another study, Treg proportions have been shown to be lower than controls within affected tissues but not in the peripheral blood [49]. A small prospective study conducted in seven SSc patients with diffuse skin phenotype found that the depressed Treg number and function were restored after autologous hematopoietic stem cell transplantation [10]. Aberrant epigenetic modifications such as hypermethylation of the FOXP3 gene have also been detected in Tregs from SSc patients and indicated as possible cause for decreased FOXP3 expression and lower circulating levels of this cell type [113]. It has been reported that X-chromosome inactivation is more skewed in SSc than in the general population and that this is not related to age. Skewed X chromosome usage correlates with lower FOXP3 expression in the CD25+ high Treg cells [17]. An intriguing twist to this topic has been brought about by the demonstration that FOXP3-positive cells with high IL-4 and IL-13 production are enriched in the skin of SSc patients compared to normal controls [64]. The authors concluded that these FOXP3 + T cells may indeed be Tregs with a functional Th2-like phenotype, which could contribute to enhance a profibrotic response in dermal fibroblasts. Of interest, this study also found that skin-infiltrating FOXP3 + T cells express high levels of the IL-33 receptor ST2 [64] and that the number of IL-13-producing FOXP3 + T cells is increased by culturing SSc skin biopsies in the presence of IL-33. This, together with 
the fact that only the skin but not peripheral blood FOXP3 + T cells manifested this aberrant Th2-like behavior, further supports the possibility that the skin of SSc patients provides the appropriate environment for transdifferentiation of Tregs (CD4+FOXP3 + T cells) toward a Th2-like phenotype with the consequent amplification of a pro-fibrotic loop.

Th17 cells In the presence of TGF- $\beta$, IL- 6 , and IL- 1 or IL- 1 and IL-23 to which IL-21 may also contribute, naïve CD4+ T cells initiate a differentiation program leading to a specialized subset of helper cells characterized by the preferential production of IL-17, henceforth named Th17 cells $[3,126]$. Th17 cells produce high levels of IL-17A, IL-17F, IL-21, IL-22, CCL20; express the master transcription factors retinoic acid nuclear orphan receptor (ROR) $\gamma \mathrm{T}$ and ROR $\alpha$; and depend on signal transducer and activator of transcription-3 (STAT-3). Th17 cells exert homeostatic functions such as protection against extracellular bacteria and fungi but have been also involved in the pathogenesis of several inflammatory and autoimmune disorders $[20,54]$. While the frequency of Th17 lymphocytes is low in the peripheral blood of healthy individuals $(\sim 1 \%)$, this subset undergoes recruitment and expansion in sites of active inflammation and tissue damage [4]. Increased levels of IL-17 and Th17 cells have been found in the peripheral blood as well as within target tissues (i.e., the skin) of SSc patients particularly during early phases and in association with ILD $[27,62,63,73,86,89,106,108,120]$. In addition, cytokines crucial for Th17 T cell priming and expansion such as IL- 6 and IL-23 have been reported enriched in SSc subjects, and a polymorphism of the IL-23 receptor gene (IL23R) has shown association with diffuse SSc and antitopoisomerase 1 positivity $[1,41,50]$. In animal models, IL17A does mediate fibrosis and SSc-like manifestations, as shown in the lungs and skin of the bleomycin as well as tight skin-1 (TSK-1/+) mice [37, 74, 79, 115]. Furthermore, Th17polarized responses mediated lung fibrosis in a model of chronic hypersensitivity [102]. Consistently, IL-17A can also drive the activation of TGF- $\beta$ and connective tissue growth factor (CTGF) pathways in fibroblasts derived from mouse skin and promote collagen production after epithelialmesenchymal transition in mouse alveolar epithelial cells in a TGF- $\beta$-dependent manner [74]. Human fibroblasts express functional IL-17 receptors and respond to IL-17A stimulation with proliferation, IL-6, IL-8 production, and ICAM-1 expression $[31,56]$. However, Nakashima et al. reported that IL-17A exerts direct anti-fibrogenic properties towards normal human fibroblasts by upregulating miR-129-5p and downregulating CTGF and type I collagen [76]. SSc fibroblasts may escape this repressive effect of IL-17A because of the reduced expression of the IL-17RA subunit [76]. Others have found that IL17A failed to increase type I and type III procollagen mRNA expressions in fibroblasts from healthy controls and SSc patients [56]. Our own findings support the contention that IL-
17A does not favor type I collagen production by healthy and SSc fibroblasts but rather limits the transdifferentiation of fibroblasts into pro-fibrotic myofibroblasts, simultaneously favoring the production of IL-8, IL-6, MCP-1, and MMP-1 [15, $63,108]$. Thus, the bulk of evidence in humans, as opposed to rodents, indicates that IL-17 and in particular IL-17A simultaneously exert anti-fibrotic and pro-inflammatory activities, which net result may be that of containing rather than enhancing extracellular matrix (ECM) deposition (Fig. 2). In this perspective, it is worth stressing that IL-17A activates endothelial cells, thus favoring inflammatory cell recruitment [119]. We have preliminary evidence indicating that IL-22 (which is produced by Th17 cells as well as by Th22 cells) shares these properties with IL-17 ([15], under revision). In this context, it is of interest to find that the majority of the cells positive for IL-17A in a normal skin are mast cells, which may engulf IL-17A from the extracellular milieu and release it upon degranulation (T. Noordenbos et al., Human mast cells engulf and store exogenous IL-17A. Oral communication 0226, EULAR, Paris, June 2014), although this has not been proven in SSc. In addition to IL-17A, other members of the IL-17 family have been documented in SSc, including IL-17F, IL-17C, and IL-17E (also known as IL-25). High IL-17E and low IL-17C dermal expression characterizes SSc as well as morphea when compared to healthy skin, thus suggesting that this expression pattern may be functionally linked to skin fibrosis [63]. However, since IL-17C does not directly act on fibroblasts and IL-17E enhances fibroblast inflammatory responses rather than collagen deposition, it could be possible that their effects are mediated by third party cells, including keratinocytes and macrophages. In this respect, it is worth noting that epithelial cells are the preferential targets of IL17 family members and IL-22. Thus, the models in which the activities of these cytokines are studied should take into account the complex network of events, which are likely to take place in the skin and other organs undergoing fibrosis, notably the lung, where epithelial cells may play a role which is only now being unraveled.

Time-dependent changes Cutaneous mononuclear cell infiltrates are notably pronounced early or during the edematousinflammatory phase of SSc and then tend to disappear with transition to the sclerotic phase. Consistently, the majority of infiltrating $\mathrm{T}$ cells in SSc skin lesions express activation markers and secrete products of activated T cells such as soluble CD25 (the soluble form of the high-affinity IL-2 receptor chain), which have been found in fluid obtained from suction skin blister of SSc patients with early cutaneous disease [104]. A limited number of studies have examined biological samples obtained specifically early on after disease initiation or at later stages, documenting variability in the expression of T cell products or soluble mediators relevant for $\mathrm{T}$ cell polarization during the course of the disease. Data are not uniform as some 


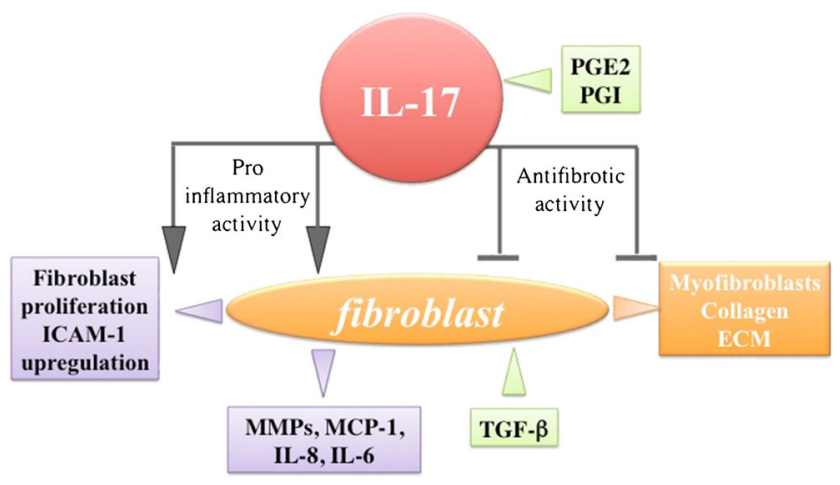

Fig. 2 IL-17 exerts a wide array of different activities on human fibroblasts, which may vary according to the context in which they take place. Arrows and arrowheads indicate stimulation; blunted-ends indicate inhibition. Green boxes: endogenous and exogenous mediators that modify the context

authors have reported a higher frequency of Th1 cells in the peripheral blood and increased serum levels of IL-12, a cytokine favoring Th1 cell differentiation, in SSc patients during later phases of the disease, when fibrosis tends to regress [96, $98,110]$. Time-dependent changes have also been reported for IL-27, with higher serum levels early on followed by lower levels in late disease [122]. This suggests that IL-27 may contribute to the dysregualtion of the adaptive immune response in SSc pathogenesis.

\section{Adhesion molecules and $\mathbf{T}$ cell polarization in fibrosis An} unresolved issue in SSc is the identification of the driving forces leading to expanded Th2-like and Th17-polarized T cell responses in SSc. In this regard, an interesting contribution has been provided by in vivo experiments conducted in animal models recapitulating the phenotype of the stiff skin syndrome (SSS), a rare Mendelian disorder leading to diffuse skin fibrosis during childhood with autosomal dominant inheritance and complete penetrance. SSS is caused by heterozygous missense mutation FBN1, the gene encoding for fibrillin-1, the main constituent of extracellular microfibrils. Mutations causing SSS all localize in the only domain (TB4) of fibrillin-1 containing an Arg-Gly-Asp (RGD) motif, which mediates cellmatrix interactions by binding to cell-surface integrins. In this study, Gerber et al. showed that mice carrying the same mutations developed aggressive skin fibrosis associated with increased infiltrates of Th2 and Th17 cells, plasmacytoid dendritic cells ( $\mathrm{pDC}$ ), and B cells within the dermal layers. Integrin modulation or neutralization of TGF- $\beta$ reversed this phenotype [38]. As such, this model support the hypothesis that abnormal assembling of the ECM can modify the availability of key mediators such as TGF- $\beta$, providing a favorable environment for the polarization of $\mathrm{T}$ cell responses toward stereotyped Th2 and Th17 expansion. Further experimental approaches are clearly needed to assess to which extent these data are applicable to SSc.
CD40-CD40 ligand interactions in SSe Fibroblasts carry on their surface CD40 and can respond upon engagement of this receptor by CD40L (CD154), a member of the TNF family, expressed by activated T cells. Of interest, CD40 is upregulated on SSc fibroblasts and T cells from SSc patients exhibit a higher expression of CD40L. In addition, serum levels of both soluble CD40 and CD40L molecules are increased in SSc [34, $51,53]$. All these findings, together with the fact that blockade of the CD40-CD40L interaction attenuates fibrosis in the TSK-1 mouse model, indicate a possible role for this biologic axis in fibrogenesis $[48,52]$.

\section{Autoantigen-dependent $\mathrm{T}$ cell responses in SSc}

The detection of expanded oligoclonal T cell subsets in affected skin or lungs (BALF) of SSc patients supports the notion that an antigen-driven, $T$ cell-dependent process may be involved in SSc pathogenesis [26, 59, 82, 93, 124]. In line with these findings, $\mathrm{T}$ cells recognizing $\mathrm{SSc}$-specific autoantigens such as topoisomerase-1 (topo-1) or RNA polymerase III (RNApol3) have been documented in humans [13, 44, 46, 57]. Most studies pursuing the detection of topo-1-specific $T$ cells in the peripheral blood of SSc patients have been limited by poor clinical characterization of involved subjects and by the existence of technical challenges to detect ex vivo lowfrequency antigen-specific $\mathrm{T}$ cells, particularly in patients receiving immunosuppression. In fact, in many cases, the detection of autoreactive $\mathrm{T}$ cells has shown poor specificity as they were found also in anti-topo-1-negative patients as well as healthy controls [58, 81, 88, 112]. More recently, a close temporal association between the onset of SSc and the detection of cancer has been described in a subset of patients positive for anti-RNA polymerase III antibodies [101]. This observation has lead to the discovery that mutated autoantigens (RNApol3) are present in the tumors obtained from these patients and result in mutant-specific $\mathrm{T}$ cell immune responses as well as in the generation cross-reactive autoantibodies [46]. These findings support the possibility that, at least in some patients, an abnormal (mutated) cancer antigen may be the initial trigger for the autoimmune response in SSc. Despite this available evidence, no conclusive data have yet been provided to define whether autoantigen-specific $\mathrm{T}$ cell responses are amplified in SSc patients with active disease and contribute to the generation of distinct phenotypes through their effector function. Investigators tested in animal models whether the generation of autoimmune responses against topo- 1 could drive a pathology resembling SSc. The immunization of mice prone to autoimmunity with the human recombinant protein induced the development of $\mathrm{T}$ cell responses and antibodies against topo-1 but did not drive any pathologic features resembling SSc [43]. In contrast, when C57BL/6 mice were repeatedly immunized with human topo- 1 in the presence of 
complete Freund's adjuvant, skin and lung fibroses in addition to autoimmune manifestations were generated [123]. Of interest, pathologic manifestations were associated with the increased production of IL- 6 and IL-17 as well as higher levels of circulating IL-17-secreting T cells (Th17). This landmark report, which is still awaiting confirmation, indicates that beside an autoimmune background, a second trigger is needed, such as the one provided by repeated stimulation of the innate immune system by complete Freund's adjuvant, to direct the immune response toward a permissive pro-fibrotic milieu.

A further contribution to support the antigen-driven nature of the immune response in SSc comes from the observation that a higher proportion of SSc women have circulating male cells compared to controls. This, together with the fact that male cells can be recovered from tissues undergoing fibrosis, suggests that alloreactive T cells may be involved in SSc pathogenesis $[8,77]$. The hypothesis that microchimerism may be mechanistically linked to SSc has also been driven by the close similarity between fibrotic skin lesions observed in SSc and graft-versus-host disease (GVHD) after allogeneic bone marrow transplantation. In fact, murine models of fibrosis have been developed based on chimerism and GVHD [125].

Overall, these data lend support to the concept that $\mathrm{T}$ cells upon nominal antigen recognition may initiate an inflammatory process ultimately resulting in tissue fibrosis. It remains however possible that $\mathrm{T}$ cells may be only activated bystanders with functional characteristics depending on and not causing the underlying disease process. Furthermore, the possibility that $\mathrm{T}$ cells, at least in certain phases of the disease, may restrain rather than favor fibrosis cannot be fully disregarded.

\section{$B$ cells in SSc and fibrosis}

Abnormal homeostasis and function of B cells have been implicated in the onset and progression of different systemic autoimmune disorders including scleroderma. Lesional skin and affected lung tissues from subjects with SSc demonstrate prominent $\mathrm{B}$ cell infiltration and a significant upregulation of $B$ cell-related genes in affected SSc skin $[60,114]$. Analysis of circulating B cell repertoire in SSc has shown expansion of the (CD27-)naïve B cell subset and the concurrent decline of memory B cell and plasmacellular components [95]. However, these memory B cells retain a strong immunoglobulin secretory function and exhibit upregulation of co-stimulatory molecules (CD80 and CD86) and CD95, suggesting a chronic activation state and an increased sensitivity to pro-apoptotic stimuli [95]. Accordingly, the expression of positive response regulators such as CD19 and the associated molecule CD21 (complement receptor type 2) are increased in naïve as well as memory B cells of SSc patients compared to healthy controls [95, 97]. A single nucleotide polymorphism (SNP) in the upstream region of CD19 gene has been associated with higher expression of this molecule in circulating B cells and susceptibility to SSc [109]. Loss of CD19 expression attenuates skin and lung fibrosis in the bleomycin-induced SSc mouse model [121]. It is possible that some subset of B cells could exert some regulatory or suppressive activity, with consequent inhibition of fibrosis. In fact, in a murine model of sclerodermatous chronic graft-versus-host disease, CD19 deficiency in donor B cells resulted in an exaggerated fibrotic response characterized by increased numbers of $\mathrm{Th} 2$ cells and enhanced production of TGF- $\beta$ by macrophages in the involved skin. Such phenotype was attenuated by the infusion of donor B cells producing IL-10, consistently with a role for suppressor B cells in controlling fibrosis [61].

A proliferation-inducing ligand (APRIL) and B cell activating factor (BAFF) are members of the tumor necrosis factor (TNF) superfamily exerting important homeostatic functions on B cells such as maturation, activation, and survival (antiapoptotic) [65]. Serum levels of BAFF and APRIL are increased in SSc patients compared to controls and are associated with specific clinical manifestations such as extent of skin involvement (BAFF) and the presence of pulmonary fibrosis (APRIL) [68, 69]. Secretion of APRIL from PBMCs was significantly higher in SSc patients compared to controls and was associated with diffuse skin phenotype, the presence of ILD, and anti-Scl70 positivity among other SSc clinical features [11]. In addition, B cells were shown to induce contactdependent human dermal fibroblasts activation with upregulation of, among other mediators, type I collagen. This B cell activity was enhanced by $B$ cell activation in the presence of anti-IgM and BAFF [32]. Interestingly, BAFF serum levels are increased in the tight-skin $(\mathrm{TSK} /+)$ mouse model and blockade of the BAFF/BAFF-receptor interaction can prevent the development of skin fibrosis, inhibit autoantibody generation, and increase the production of anti-fibrotic cytokines (i.e., IFN- $\gamma$ ) [67]. In a bleomycin-induced model of pulmonary fibrosis, BAFF neutralization or BAFF gene deletion resulted in attenuated fibrosis. Of interest, BAFF production in that model was IL-1 and IL-17A-dependent and acted as an amplifying positive loop for IL-17A production by $\mathrm{T}$ cells [33]. All these data indicate that B cell activation and over activity are important features of the immune response in SSc, and that an imbalance of B cell homeostasis and function may contribute to the amplification of the inflammatory as well as fibrotic process in this disease.

\section{Conclusions}

T cells play distinct roles in SSc with regard to their ability to modulate the activity of fibroblasts and the turnover of ECM. This effector function mostly depends on the biological effects of the cytokines they produce (Figs. 1 and 2). They also drive 
inflammatory responses, which can involve concurrently fibroblasts, endothelial, and epithelial cells. An imbalanced T regulatory function also seems to contribute to altered immune homeostasis in SSc. Defective B cells appear to exert pathogenetic functions beyond the mere production of autoantibodies and possibly include the ability to directly influence fibroblast activation. The main challenge ahead of us is to improve our ability to characterize dynamically the adaptive immune response as SSc progresses through its different stages (i.e., early vs late) and to define the key mediators driving the different SSc clinical phenotypes. Ultimately, it is likely that the significance of stereotyped immune responses observed in SSc vary according to the specific tissue, cellular, and biochemical environment in which they take place. Deciphering context-specific responses will lead to novel, fine-tuned, targeted therapeutic approaches.

\section{References}

1. Agarwal SK, Gourh P, Shete S, Paz G, Divecha D, Reveille JD et al (2009) Association of interleukin 23 receptor polymorphisms with anti-topoisomerase-I positivity and pulmonary hypertension in systemic sclerosis. J Rheumatol 36:2715-2723

2. Allanore Y, Saad M, Dieude P, Avouac J, Distler JH, Amouyel P et al (2011) Genome-wide scan identifies TNIP1, PSORS1C1, and RHOB as novel risk loci for systemic sclerosis. PLoS Genet 7, e1002091

3. Annunziato F, Cosmi L, Liotta F, Maggi E, Romagnani S (2009) Type $17 \mathrm{~T}$ helper cells - origins, features and possible roles in rheumatic disease. Nat Rev Rheumatol 5:325-331

4. Annunziato F, Cosmi L, Santarlasci V, Maggi L, Liotta F, Mazzinghi B et al (2007) Phenotypic and functional features of human Th17 cells. J Exp Med 204:1849-1861

5. Annunziato F, Romagnani S (2009) Heterogeneity of human effector CD4+ T cells. Arthritis Res Ther 11:257

6. Antiga E, Quaglino P, Bellandi S, Volpi W, Del Bianco E, Comessatti A et al (2010) Regulatory T cells in the skin lesions and blood of patients with systemic sclerosis and morphoea. Br J Dermatol 162:1056-1063

7. Arnett FC, Gourh P, Shete S, Ahn CW, Honey RE, Agarwal SK et al (2010) Major histocompatibility complex (MHC) class II alleles, haplotypes and epitopes which confer susceptibility or protection in systemic sclerosis: analyses in 1300 Caucasian, African-American and Hispanic cases and 1000 controls. Ann Rheum Dis 69:822-827

8. Artlett CM, Smith JB, Jimenez SA (1998) Identification of fetal DNA and cells in skin lesions from women with systemic sclerosis. N Engl J Med 338:1186-1191

9. Atamas SP, Yurovsky VV, Wise R, Wigley FM, Goter Robinson CJ, Henry P et al (1999) Production of type 2 cytokines by CD8+ lung cells is associated with greater decline in pulmonary function in patients with systemic sclerosis. Arthritis Rheum 42:1168-1178

10. Baraut J, Grigore EI, Jean-Louis F, Khelifa SH, Durand C, Verrecchia $\mathrm{F}$ et al (2014) Peripheral blood regulatory T cells in patients with diffuse systemic sclerosis (SSc) before and after autologous hematopoietic SCT: a pilot study. Bone Marrow Transplant 49:349-354
11. Bielecki M, Kowal K, Lapinska A, Bernatowicz P, Chyczewski L, Kowal-Bielecka O (2010) Increased production of a proliferationinducing ligand (APRIL) by peripheral blood mononuclear cells is associated with antitopoisomerase I antibody and more severe disease in systemic sclerosis. J Rheumatol 37:2286-2289

12. Boin F, De Fanis U, Bartlett SJ, Wigley FM, Rosen A, Casolaro V (2008) T cell polarization identifies distinct clinical phenotypes in scleroderma lung disease. Arthritis Rheum 58:1165-1174

13. Boin F, Wigley FM, Schneck JP, Oelke M, Rosen A (2005) Evaluation of topoisomerase-1-specific CD8+ T-cell response in systemic sclerosis. Ann N Y Acad Sci 1062:137-145

14. Bossini-Castillo L, Martin JE, Broen J, Gorlova O, Simeon CP, Beretta L et al (2012) A GWAS follow-up study reveals the association of the IL12RB2 gene with systemic sclerosis in Caucasian populations. Hum Mol Genet 21:926-933

15. Brembilla NC, Montanari E, Truchetet ME, Raschi E, Meroni P, Chizzolini C (2013) Th17 cells favor inflammatory responses while inhibiting type I collagen deposition by dermal fibroblasts: differential effects in healthy and systemic sclerosis fibroblasts. Arthritis Res Ther 15:R151

16. Broen JC, Dieude P, Vonk MC, Beretta L, Carmona FD, Herrick A et al (2012) Polymorphisms in the interleukin 4, interleukin 13, and corresponding receptor genes are not associated with systemic sclerosis and do not influence gene expression. J Rheumatol 39: $112-118$

17. Broen JC, Wolvers-Tettero IL, Geurts-van Bon L, Vonk MC, Coenen MJ, Lafyatis R, et al (2010) Skewed X chromosomal inactivation impacts $\mathrm{T}$ regulatory cell function in systemic sclerosis. Ann Rheum Dis 69:2213-16

18. Burt RK, Oliveira MC, Shah SJ, Moraes DA, Simoes B, Gheorghiade $\mathrm{M}$ et al (2013) Cardiac involvement and treatmentrelated mortality after non-myeloablative haemopoietic stem-cell transplantation with unselected autologous peripheral blood for patients with systemic sclerosis: a retrospective analysis. Lancet 381:1116-1124

19. Burt RK, Shah SJ, Dill K, Grant T, Gheorghiade M, Schroeder J et al (2011) Autologous non-myeloablative haemopoietic stemcell transplantation compared with pulse cyclophosphamide once per month for systemic sclerosis (ASSIST): an open-label, randomised phase 2 trial. Lancet 378:498-506

20. Chabaud M, Durand JM, Buchs N, Fossiez F, Page G, Frappart L et al (1999) Human interleukin-17: a T cell-derived proinflammatory cytokine produced by the rheumatoid synovium. Arthritis Rheum 42:963-970

21. Chizzolini C, Parel Y, De Luca C, Tyndall A, Akesson A, Scheja A et al (2003) Systemic sclerosis Th2 cells inhibit collagen production by dermal fibroblasts via membrane-associated tumor necrosis factor alpha. Arthritis Rheum 48:2593-2604

22. Chizzolini C, Parel Y, Scheja A, Dayer JM (2005) Polarized subsets of human $T$ helper cells induce distinct patterns of chemokine production by normal and systemic sclerosis dermal fibroblasts (abstract). Clin Exp Rheumatol 23:739

23. Chizzolini C, Rezzonico R, De Luca C, Burger D, Dayer JM (2000) Th2 cell membrane factors in association with IL-4 enhance matrix metalloproteinase-1 (MMP-1) while decreasing MMP-9 production by granulocyte-macrophage colony-stimulating factor-differentiated human monocytes. J Immunol 164:59525960

24. Chizzolini C, Rezzonico R, Ribbens C, Burger D, Wollheim FA, Dayer JM (1998) Inhibition of type I collagen production by dermal fibroblasts upon contact with activated T cells: different sensitivity to inhibition between systemic sclerosis and control fibroblasts. Arthritis Rheum 41:2039-2047

25. Del Galdo F, Jimenez SA (2007) T cells expressing allograft inflammatory factor 1 display increased chemotaxis and induce a 
profibrotic phenotype in normal fibroblasts in vitro. Arthritis Rheum 56:3478-3488

26. Farge D, Henegar C, Carmagnat M, Daneshpouy M, Marjanovic Z, Rabian C et al (2005) Analysis of immune reconstitution after autologous bone marrow transplantation in systemic sclerosis. Arthritis Rheum 52:1555-1563

27. Fenoglio D, Battaglia F, Parodi A, Stringara S, Negrini S, Panico N et al (2011) Alteration of Th17 and Treg cell subpopulations coexist in patients affected with systemic sclerosis. Clin Immunol 139:249-257

28. Ferrarini M, Steen V, Medsger TA Jr, Whiteside TL (1990) Functional and phenotypic analysis of T lymphocytes cloned from the skin of patients with systemic sclerosis. Clin Exp Immunol 79: 346-352

29. Fleischmajer R, Perlish JS, Reeves JR (1977) Cellular infiltrates in scleroderma skin. Arthritis Rheum 20:975-984

30. Fleming JN, Nash RA, McLeod DO, Fiorentino DF, Shulman HM, Connolly MK et al (2008) Capillary regeneration in scleroderma: stem cell therapy reverses phenotype? PLoS ONE 3, e1452

31. Fossiez F, Djossou O, Chomarat P, Flores-Romo L, Ait-Yahia S, Maat C et al (1996) T cell interleukin-17 induces stromal cells to produce proinflammatory and hematopoietic cytokines. J Exp Med 183:2593-2603

32. Francois A, Chatelus E, Wachsmann D, Sibilia J, Bahram S, Alsaleh G et al (2013) B lymphocytes and B-cell activating factor promote collagen and profibrotic markers expression by dermal fibroblasts in systemic sclerosis. Arthritis Res Ther 15:R168

33. Francois A, Gombault A, Villeret B, Alsaleh G, Fanny M, Gasse P et al (2015) B cell activating factor is central to bleomycin- and IL17-mediated experimental pulmonary fibrosis. J Autoimmun 56: $1-11$

34. Fukasawa C, Kawaguchi Y, Harigai M, Sugiura T, Takagi K, Kawamoto M et al (2003) Increased CD40 expression in skin fibroblasts from patients with systemic sclerosis $(\mathrm{SSc})$ : role of CD40-CD154 in the phenotype of SSc fibroblasts. Eur J Immunol 33:2792-2800

35. Fuschiotti P, Larregina AT, Ho J, Feghali-Bostwick C, Medsger TA Jr (2013) Interleukin-13-producing CD8+ T cells mediate dermal fibrosis in patients with systemic sclerosis. Arthritis Rheum 65:236-246

36. Fuschiotti P, Medsger TA Jr, Morel PA (2009) Effector CD8+ T cells in systemic sclerosis patients produce abnormally high levels of interleukin-13 associated with increased skin fibrosis. Arthritis Rheum 60:1119-1128

37. Gasse P, Riteau N, Vacher R, Michel ML, Fautrel A, di Padova F et al (2011) IL-1 and IL-23 mediate early IL-17A production in pulmonary inflammation leading to late fibrosis. PLoS ONE 6, e23185

38. Gerber EE, Gallo EM, Fontana SC, Davis EC, Wigley FM, Huso DL et al (2013) Integrin-modulating therapy prevents fibrosis and autoimmunity in mouse models of scleroderma. Nature 503:126130

39. Gorlova O, Martin JE, Rueda B, Koeleman BP, Ying J, Teruel M et al (2011) Identification of novel genetic markers associated with clinical phenotypes of systemic sclerosis through a genome-wide association strategy. PLoS Genet 7, e1002178

40. Gorlova O, Martin JE, Rueda B, Koeleman BP, Ying J, Teruel M et al (2011) Correction: identification of novel genetic markers associated with clinical phenotypes of systemic sclerosis through a genome-wide association strategy. PLoS Genet 7:e1002178

41. Gourh P, Arnett FC, Assassi S, Tan FK, Huang M, Diekman L et al (2009) Plasma cytokine profiles in systemic sclerosis: associations with autoantibody subsets and clinical manifestations. Arthritis Res Ther 11:R147
42. Hoffmann KF, McCarty TC, Segal DH, Chiaramonte M, Hesse M, Davis EM et al (2001) Disease fingerprinting with cDNA microarrays reveals distinct gene expression profiles in lethal type 1 and type 2 cytokine-mediated inflammatory reactions. FASEB J 15: 2545-2547

43. Hu PQ, Hurwitz AA, Oppenheim JJ (2007) Immunization with DNA topoisomerase I induces autoimmune responses but not scleroderma-like pathologies in mice. J Rheumatol 34:2243-2252

44. Hu PQ, Oppenheim JJ, Medsger TA Jr, Wright TM (2006) T cell lines from systemic sclerosis patients and healthy controls recognize multiple epitopes on DNA topoisomerase I. J Autoimmun 26: 258-267

45. Hugle T, O'Reilly S, Simpson R, Kraaij MD, Bigley V, Collin M et al (2013) Tumor necrosis factor-costimulated T lymphocytes from patients with systemic sclerosis trigger collagen production in fibroblasts. Arthritis Rheum 65:481-491

46. Joseph CG, Darrah E, Shah AA, Skora AD, Casciola-Rosen LA, Wigley FM et al (2014) Association of the autoimmune disease scleroderma with an immunologic response to cancer. Science 343:152-157

47. Kahari VM, Sandberg M, Kalimo H, Vuorio T, Vuorio E (1988) Identification of fibroblasts responsible for increased collagen production in localized scleroderma by in situ hybridization. $\mathrm{J}$ Investig Dermatol 90:664-670

48. Kawai M, Masuda A, Kuwana M (2008) A CD40-CD154 interaction in tissue fibrosis. Arthritis Rheum 58:3562-3573

49. Klein S, Kretz CC, Ruland V, Stumpf C, Haust M, Hartschuh W, et al (2010) Reduction of regulatory T cells in skin lesions but not in peripheral blood of patients with systemic scleroderma. Ann Rheum Dis 70:1475-81

50. Komura K, Fujimoto M, Hasegawa M, Ogawa F, Hara T, Muroi E et al (2008) Increased serum interleukin 23 in patients with systemic sclerosis. J Rheumatol 35:120-125

51. Komura K, Fujimoto M, Matsushita T, Yanaba K, Kodera M, Kawasuji A et al (2007) Increased serum soluble CD40 levels in patients with systemic sclerosis. J Rheumatol 34:353-358

52. Komura K, Fujimoto M, Yanaba K, Matsushita T, Matsushita Y, Horikawa $\mathrm{M}$ et al (2008) Blockade of CD40/CD40 ligand interactions attenuates skin fibrosis and autoimmunity in the tight-skin mouse. Ann Rheum Dis 67:867-872

53. Komura K, Sato S, Hasegawa M, Fujimoto M, Takehara K (2004) Elevated circulating CD40L concentrations in patients with systemic sclerosis. J Rheumatol 31:514-519

54. Korn T, Bettelli E, Oukka M, Kuchroo VK (2009) IL-17 and Th17 cells. Annu Rev Immunol 27:485-517

55. Kreuter A, Hoxtermann S, Tigges C, Hahn SA, Altmeyer P, Gambichler T (2009) Clonal T-cell populations are frequent in the skin and blood of patients with systemic sclerosis. Br J Dermatol 161:785-790

56. Kurasawa K, Hirose K, Sano H, Endo H, Shinkai H, Nawata Y et al (2000) Increased interleukin-17 production in patients with systemic sclerosis. Arthritis Rheum 43:2455-2463

57. Kuwana M, Feghali CA, Medsger TA Jr, Wright TM (2001) Autoreactive $\mathrm{T}$ cells to topoisomerase I in monozygotic twins discordant for systemic sclerosis. Arthritis Rheum 44:1654-1659

58. Kuwana M, Medsger TA Jr, Wright TM (1995) T cell proliferative response induced by DNA topoisomerase I in patients with systemic sclerosis and healthy donors. J Clin Invest 96:586-596

59. Kuwana M, Medsger TA Jr, Wright TM (1997) Highly restricted TCR-alpha beta usage by autoreactive human T cell clones specific for DNA topoisomerase I: recognition of an immunodominant epitope. J Immunol 158:485-491

60. Lafyatis R, O'Hara C, Feghali-Bostwick CA, Matteson E (2007) B cell infiltration in systemic sclerosis-associated interstitial lung disease. Arthritis Rheum 56:3167-3168 
61. Le Huu D, Matsushita T, Jin G, Hamaguchi Y, Hasegawa M, Takehara K et al (2013) Donor-derived regulatory B cells are important for suppression of murine sclerodermatous chronic graft-versus-host disease. Blood 121:3274-3283

62. Liu X, Gao N, Li M, Xu D, Hou Y, Wang Q et al (2013) Elevated levels of CD4(+)CD25(+)FoxP3(+) T cells in systemic sclerosis patients contribute to the secretion of IL-17 and immunosuppression dysfunction. PLoS ONE 8, e64531

63. Lonati PA, Brembilla NC, Montanari E, Fontao L, Gabrielli A, Vettori S et al (2014) High IL-17E and low IL-17C dermal expression identifies a fibrosis-specific motif common to morphea and systemic sclerosis. PLoS ONE 9, e105008

64. MacDonald KG, Dawson NA, Huang Q, Dunne JV, Levings MK, Broady R (2015) Regulatory T cells produce profibrotic cytokines in the skin of patients with systemic sclerosis. J Allergy Clin Immunol 135:946-55.e9

65. Mackay F, Browning JL (2002) BAFF: a fundamental survival factor for B cells. Nat Rev Immunol 2:465-475

66. Mathian A, Parizot C, Dorgham K, Trad S, Arnaud L, Larsen M et al (2012) Activated and resting regulatory T cell exhaustion concurs with high levels of interleukin-22 expression in systemic sclerosis lesions. Ann Rheum Dis 71:1227-1234

67. Matsushita T, Fujimoto M, Hasegawa M, Matsushita Y, Komura $\mathrm{K}$, Ogawa F et al (2007) BAFF antagonist attenuates the development of skin fibrosis in tight-skin mice. J Investig Dermatol 127: 2772-2780

68. Matsushita T, Fujimoto M, Hasegawa M, Tanaka C, Kumada S, Ogawa $\mathrm{F}$ et al (2007) Elevated serum APRIL levels in patients with systemic sclerosis: distinct profiles of systemic sclerosis categorized by APRIL and BAFF. J Rheumatol 34:2056-2062

69. Matsushita T, Hasegawa M, Yanaba K, Kodera M, Takehara K, Sato S (2006) Elevated serum BAFF levels in patients with systemic sclerosis: enhanced BAFF signaling in systemic sclerosis B lymphocytes. Arthritis Rheum 54:192-201

70. Mavalia C, Scaletti C, Romagnani P, Carossino AM, Pignone A, Emmi L et al (1997) Type 2 helper T-cell predominance and high CD30 expression in systemic sclerosis. Am J Pathol 151:17511758

71. Mayes MD, Bossini-Castillo L, Gorlova O, Martin JE, Zhou X, Chen WV et al (2014) Immunochip analysis identifies multiple susceptibility loci for systemic sclerosis. Am J Hum Genet 94: 47-61

72. Medsger TA Jr, Ivanco DE, Kardava L, Morel PA, Lucas MR, Fuschiotti P (2011) GATA-3 up-regulation in CD8+ T cells as a biomarker of immune dysfunction in systemic sclerosis, resulting in excessive interleukin-13 production. Arthritis Rheum 63:17381747

73. Meloni F, Solari N, Cavagna L, Morosini M, Montecucco CM, Fietta AM (2009) Frequency of Th1, Th2 and Th17 producing T lymphocytes in bronchoalveolar lavage of patients with systemic sclerosis. Clin Exp Rheumatol 27:765-772

74. Mi S, Li Z, Yang HZ, Liu H, Wang JP, Ma YG et al (2011) Blocking IL-17A promotes the resolution of pulmonary inflammation and fibrosis via TGF-beta1-dependent and -independent mechanisms. J Immunol 187:3003-3014

75. Miyara M, Yoshioka Y, Kitoh A, Shima T, Wing K, Niwa A et al (2009) Functional delineation and differentiation dynamics of human CD4+ T cells expressing the FoxP3 transcription factor. Immunity 30:899-911

76. Nakashima T, Jinnin M, Yamane K, Honda N, Kajihara I, Makino Tet al (2012) Impaired IL-17 signaling pathway contributes to the increased collagen expression in scleroderma fibroblasts. J Immunol 188:3573-3583

77. Nelson JL, Furst DE, Maloney S, Gooley T, Evans PC, Smith A et al (1998) Microchimerism and HLA-compatible relationships of pregnancy in scleroderma. Lancet 351:559-562
78. Ohkura N, Kitagawa Y, Sakaguchi S (2013) Development and maintenance of regulatory T cells. Immunity 38:414-423

79. Okamoto Y, Hasegawa M, Matsushita T, Hamaguchi Y, Huu DL, Iwakura $\mathrm{Y}$ et al (2012) Potential roles of interleukin-17A in the development of skin fibrosis in mice. Arthritis Rheum 64:37263735

80. Oriente A, Fedarko NS, Pacocha SE, Huang SK, Lichtenstein LM, Essayan DM (2000) Interleukin-13 modulates collagen homeostasis in human skin and keloid fibroblasts. J Pharmacol Exp Ther 292:988-994

81. Oriss TB, Hu PQ, Wright TM (2001) Distinct autoreactive T cell responses to native and fragmented DNA topoisomerase I: influence of APC type and IL-2. J Immunol 166:5456-5463

82. Parel Y, Aurrand-Lions M, Scheja A, Dayer JM, Roosnek E, Chizzolini C (2007) Presence of CD4+CD8+ double-positive T cells with very high interleukin-4 production potential in lesional skin of patients with systemic sclerosis. Arthritis Rheum 56:3459 3467

83. Postlethwaite AE, Holness MA, Katai H, Raghow R (1992) Human fibroblasts synthesize elevated levels of extracellular matrix proteins in response to interleukin 4. J Clin Invest 90:14791485

84. Prescott RJ, Freemont AJ, Jones CJ, Hoyland J, Fielding P (1992) Sequential dermal microvascular and perivascular changes in the development of scleroderma. J Pathol 166:255-263

85. Radstake TR, Gorlova O, Rueda B, Martin JE, Alizadeh BZ, Palomino-Morales R et al (2010) Genome-wide association study of systemic sclerosis identifies CD247 as a new susceptibility locus. Nat Genet 42:426-429

86. Radstake TR, van Bon L, Broen J, Hussiani A, Hesselstrand R, Wuttge DM et al (2009) The pronounced Th17 profile in systemic sclerosis (SSc) together with intracellular expression of TGFbeta and IFNgamma distinguishes SSc phenotypes. PLoS ONE 4, e5903

87. Radstake TR, van Bon L, Broen J, Wenink M, Santegoets K, Deng Y et al (2009) Increased frequency and compromised function of T regulatory cells in systemic sclerosis (SSc) is related to a diminished CD69 and TGFbeta expression. PLoS ONE 4, e5981

88. Rands AL, Whyte J, Cox B, Hall ND, McHugh NJ (2000) MHC class II associations with autoantibody and $\mathrm{T}$ cell immune responses to the scleroderma autoantigen topoisomerase I. J Autoimmun 15:451-458

89. Rodriguez-Reyna TS, Furuzawa-Carballeda J, Cabiedes J, Fajardo-Hermosillo LD, Martinez-Reyes C, Diaz-Zamudio M, et al (2011) Th17 peripheral cells are increased in diffuse cutaneous systemic sclerosis compared with limited illness: a crosssectional study. Rheumatol Int 32:2653-60

90. Rosenbloom J, Feldman G, Freundlich B, Jimenez SA (1986) Inhibition of excessive scleroderma fibroblast collagen production by recombinant gamma-interferon. Association with a coordinate decrease in types I and III procollagen messenger RNA levels. Arthritis Rheum 29:851-856

91. Sakaguchi S, Miyara M, Costantino CM, Hafler DA (2010) FOXP3+ regulatory $\mathrm{T}$ cells in the human immune system. Nat Rev Immunol 10:490-500

92. Sakaguchi S, Vignali DA, Rudensky AY, Niec RE, Waldmann H (2013) The plasticity and stability of regulatory T cells. Nat Rev Immunol 13:461-467

93. Sakkas LI, Xu B, Artlett CM, Lu S, Jimenez SA, Platsoucas CD (2002) Oligoclonal T cell expansion in the skin of patients with systemic sclerosis. J Immunol 168:3649-3659

94. Sandler NG, Mentink-Kane MM, Cheever AW, Wynn TA (2003) Global gene expression profiles during acute pathogen-induced pulmonary inflammation reveal divergent roles for Th1 and Th2 responses in tissue repair. J Immunol 171:3655-3667 
95. Sato S, Fujimoto M, Hasegawa M, Takehara K (2004) Altered blood B lymphocyte homeostasis in systemic sclerosis: expanded naive B cells and diminished but activated memory B cells. Arthritis Rheum 50:1918-1927

96. Sato S, Hanakawa H, Hasegawa M, Nagaoka T, Hamaguchi Y, Nishijima C et al (2000) Levels of interleukin 12, a cytokine of type 1 helper T cells, are elevated in sera from patients with systemic sclerosis. J Rheumatol 27:2838-2842

97. Sato S, Hasegawa M, Fujimoto M, Tedder TF, Takehara K (2000) Quantitative genetic variation in CD19 expression correlates with autoimmunity. J Immunol 165:6635-6643

98. Sato S, Hasegawa M, Takehara K (2001) Serum levels of interleukin-6 and interleukin-10 correlate with total skin thickness score in patients with systemic sclerosis. J Dermatol Sci 27:140 146

99. Scaletti C, Vultaggio A, Bonifacio S, Emmi L, Torricelli F, Maggi E et al (2002) Th2-oriented profile of male offspring T cells present in women with systemic sclerosis and reactive with maternal major histocompatibility complex antigens. Arthritis Rheum 46: $445-450$

100. Scharffetter K, Lankat-Buttgereit B, Krieg T (1988) Localization of collagen mRNA in normal and scleroderma skin by in-situ hybridization. Eur J Clin Investig 18:9-17

101. Shah AA, Rosen A, Hummers L, Wigley F, Casciola-Rosen L (2010) Close temporal relationship between onset of cancer and scleroderma in patients with RNA polymerase I/III antibodies. Arthritis Rheum 62:2787-2795

102. Simonian PL, Roark CL, Wehrmann F, Lanham AK, Diaz del Valle F, Born WK (2009) Th17-polarized immune response in a murine model of hypersensitivity pneumonitis and lung fibrosis. J Immunol 182:657-665

103. Slobodin G, Ahmad MS, Rosner I, Peri R, Rozenbaum M, Kessel A et al (2010) Regulatory T cells (CD4(+)CD25(bright)FoxP3(+)) expansion in systemic sclerosis correlates with disease activity and severity. Cell Immunol 261:77-80

104. Sondergaard K, Stengaard-Pedersen K, Zachariae H, Heickendorff L, Deleuran M, Deleuran B (1998) Soluble intercellular adhesion molecule-1 (sICAM-1) and soluble interleukin2 receptors (sIL-2R) in scleroderma skin. Br J Rheumatol 37: 304-310

105. Takeda K, Hatamochi A, Arakawa M, Ueki H (1993) Effects of tumor necrosis factor-alpha on connective tissue metabolism in normal and scleroderma fibroblast cultures. Arch Dermatol Res 284:440-444

106. Truchetet ME, Brembilla NC, Montanari E, Allanore Y, Chizzolini C (2011) Increased frequency of circulating Th22 in addition to Th17 and Th2 lymphocytes in systemic sclerosis: association with interstitial lung disease. Arthritis Res Ther 13:R166

107. Truchetet ME, Brembilla NC, Montanari E, Chizzolini C (2010) T-cell subsets in scleroderma patients. Expert Rev Dermatol 5: 403-415

108. Truchetet ME, Brembilla NC, Montanari E, Lonati P, Raschi E, Zeni $S$ et al (2013) Interleukin-17A+ cell counts are increased in systemic sclerosis skin and their number is inversely correlated with the extent of skin involvement. Arthritis Rheum 65:13471356

109. Tsuchiya N, Kuroki K, Fujimoto M, Murakami Y, Tedder TF, Tokunaga $\mathrm{K}$ et al (2004) Association of a functional CD19 polymorphism with susceptibility to systemic sclerosis. Arthritis Rheum 50:4002-4007

110. Valentini G, Baroni A, Esposito K, Naclerio C, Buommino E, Farzati A et al (2001) Peripheral blood T lymphocytes from systemic sclerosis patients show both Th1 and Th2 activation. J Clin Immunol 21:210-217

111. van Laar JM, Farge D, Sont JK, Naraghi K, Marjanovic Z, Larghero J et al (2014) Autologous hematopoietic stem cell transplantation vs intravenous pulse cyclophosphamide in diffuse cutaneous systemic sclerosis: a randomized clinical trial. JAMA : J Am Med Assoc 311:2490-2498

112. Veeraraghavan S, Renzoni EA, Jeal H, Jones M, Hammer J, Wells AU et al (2004) Mapping of the immunodominant T cell epitopes of the protein topoisomerase I. Ann Rheum Dis 63:982-987

113. Wang YY, Wang Q, Sun XH, Liu RZ, Shu Y, Kanekura T et al (2014) DNA hypermethylation of the forkhead box protein 3 (FOXP3) promoter in CD4+ T cells of patients with systemic sclerosis. Br J Dermatol 171:39-47

114. Whitfield ML, Finlay DR, Murray JI, Troyanskaya OG, Chi JT, Pergamenschikov A et al (2003) Systemic and cell type-specific gene expression patterns in scleroderma skin. Proc Natl Acad Sci U S A 100:12319-12324

115. Wilson MS, Madala SK, Ramalingam TR, Gochuico BR, Rosas IO, Cheever AW et al (2010) Bleomycin and IL-1beta-mediated pulmonary fibrosis is IL-17A dependent. J Exp Med 207:535-552

116. Wynn TA (2004) Fibrotic disease and the $\mathrm{T}(\mathrm{H}) 1 / \mathrm{T}(\mathrm{H}) 2$ paradigm. Nat Rev Immunol 4:583-594

117. Wynn TA (2008) Cellular and molecular mechanisms of fibrosis. J Pathol 214:199-210

118. Wynn TA (2011) Integrating mechanisms of pulmonary fibrosis. $\mathbf{J}$ Exp Med 208:1339-1350

119. Xing X, Yang J, Yang X, Wei Y, Zhu L, Gao D et al (2013) IL-17A induces endothelial inflammation in systemic sclerosis via the ERK signaling pathway. PLoS ONE 8, e85032

120. Yang X, Yang J, Xing X, Wan L, Li M (2014) Increased frequency of Th17 cells in systemic sclerosis is related to disease activity and collagen overproduction. Arthritis Res Ther 16:R4

121. Yoshizaki A, Iwata Y, Komura K, Ogawa F, Hara T, Muroi E, et al (2008) CD19 regulates skin and lung fibrosis via toll-like receptor signaling in a model of bleomycin-induced scleroderma. Am J Pathol 6:1650-63

122. Yoshizaki A, Yanaba K, Iwata Y, Komura K, Ogawa A, Muroi E et al (2011) Elevated serum interleukin-27 levels in patients with systemic sclerosis: association with $\mathrm{T}$ cell, $\mathrm{B}$ cell and fibroblast activation. Ann Rheum Dis 70:194-200

123. Yoshizaki A, Yanaba K, Ogawa A, Asano Y, Kadono T, Sato S (2011) Immunization with DNA topoisomerase I and Freund's complete adjuvant induces skin and lung fibrosis and autoimmunity via interleukin-6 signaling. Arthritis Rheum 63:3575-3585

124. Yurovsky VV, Wigley FM, Wise RA, White B (1996) Skewing of the CD8+ T-cell repertoire in the lungs of patients with systemic sclerosis. Hum Immunol 48:84-97

125. Zhang Y, McCormick LL, Desai SR, Wu C, Gilliam AC (2002) Murine sclerodermatous graft-versus-host disease, a model for human scleroderma: cutaneous cytokines, chemokines, and immune cell activation. J Immunol 168:3088-3098

126. Zhu J, Yamane H, Paul WE (2010) Differentiation of effector CD4 T cell populations (*). Annu Rev Immunol 28:445-489 